\title{
Immunohistochemical detection of prolactin in clinically non-functioning pituitary adenomas
}

\author{
Katarzyna Winczyk, Joanna Toszek, Jacek Swietoslawski, Ewa Wojtczak, Marek Pawlikowski
}

\author{
Department of Neuroendocrinology, Medical University of Lodz
}

\begin{abstract}
Introduction. Approximately one third of pituitary adenomas are manifested neither by specific symptoms of hormone overproduction nor by elevated blood levels of pituitary hormones. However, these tumours, diagnosed before surgical intervention as clinically non-functioning pituitary adenomas (CNFPAs) express in majority different pituitary hormones, as can be revealed by means of immunohistochemical examination. One of the pituitary hormones which may be expressed in CNFPAs is prolactin (PRL) but the clinical and pathological data on this condition are very scarce.

Material and methods. Sixty two pituitary adenomas, diagnosed before surgery as CNFPAs, were immunoassayed with antibodies against PRL, growth hormone $(\mathrm{GH})$, luteinizing hormone $(\mathrm{LH})$, follicle stimulating hormone (FSH), thyrotropin (TSH), alpha subunit (alpha-SU), corticotropin (ACTH) and dopamine receptor type 2. In a proportion of the patients the presurgical concentrations of insulin-like growth factor 1(IGF-1) were estimated by means of enzyme-amplified chemiluminescence assay.

Results. Twenty-three (37.1\%) of the examined CNFPAs presented the positive immunoreaction with anti-PRL antibody. Most cases concerned women. Only in two cases (one woman and one man), PRL was the unique hormone expressed in the tumour. In the remaining adenomas PRL immunopositivity was accompanied by GH expression -17 , $\mathrm{LH}$ or free $\beta \mathrm{LH}-13$, FSH -2 , free $\alpha$ subunit -4 or by ACTH -5 tumours. Seven $(30.43 \%)$ of them were recurrent in comparison with $12.8 \%$ PRL-immunonegative recurrent CNFPAs. Dopamine receptors were positively immunostained in all the investigated PRL-immunopositive and all PRL-immunonegative adenomas.

Conclusions. Our data confirm the observations that monohormonal silent prolactinomas are very rare but frequently silent PRL often co-expressed with GH or LH. Although in the whole population of patients with CNFPAs both sexes are equally represented, in the case of silent prolactinomas the female sex is prevalent. The observation of the higher rate of recurrent tumours within PRL-immunopositive adenomas versus PRL-immunonegative CNFPAs has to be confirmed on the larger material. (Folia Histochemica et Cytobiologica 2020, Vol. 58, No. 2, 90-95)
\end{abstract}

Key words: clinically non-functioning pituitary adenomas; immunohistochemistry; silent prolactinoma; GH; LH; dopamine receptors; insulin-like growth factor-1

\section{Introduction}

The pituitary adenomas usually relate to excess of pituitary hormones and lead to specific clinical symptoms of hormone over-secretion. However, the

\footnotetext{
Correspondence address: Prof. Katarzyna Winczyk MD, PhD Department of Neuroendocrinology,

Medical University of Lodz

251/A1 Pomorska Str., 92-213 Lodz, Poland

phone: +48 422014299

e-mail: katarzyna.winczyk@umed.lodz.pl
}

relatively high number of them (approximatively one third) are neither accompanied by increased hormone blood levels nor by clinical symptoms of pituitary hyperfunction. These tumours are diagnosed before surgery as clinically non-functioning pituitary adenomas (CNFPAs). Most of them present the immunohistochemical expression of different pituitary hormones, despite a lack of the clinical evidence of the hormone overproduction and increase of respective hormone levels in blood. Such tumours are called ,silent" pituitary adenomas [1-7]. The majority of CNFPAs (70$-80 \%$ ) express gonadotropins or their subunits [1-10]. 
Silent corticotropinomas (corticotroph adenomas not manifested by Cushing's disease) and somatotroph adenomas without acromegaly (silent somatotropinomas) are less frequent but not exceedingly rare [1-7, 11-19]. In contrast, silent thyrotropin-expressing [1-7, 20] and prolactin-expressing pituitary adenomas are considered as very rare and the data concerning the clinical and pathological characterization of the latter of them are very scarce $[5,7,21,22]$. The aim of the present study is to partially fill this gap.

\section{Material and methods}

Sixty-two pituitary adenomas were surgically removed in the Department of Neurosurgery and Surgery of Peripheral Nerves, Medical University of Lodz, Lodz, Poland. All the excised tumours were diagnosed before surgery as CNFPAs and after operation examined by immunohistochemistry. The samples were fixed in Bouin-Holland fixative or formalin and embedded in paraffin wax. The paraffin sections were immunoassayed generally as described before [23] with antibodies against prolactin (PRL, polyclonal, Dako, Glostrup, Denmark), growth hormone ( $\mathrm{GH}$, polyclonal, Dako, or Immunon, USA), luteinizing hormone ( $\mathrm{LH}$, monoclonal, Dako), follicle stimulating hormone (FSH, monoclonal, Dako), thyrotropin (TSH, monoclonal, Immunotech, France), alpha-subunit (alpha-SU, monoclonal, Immunotech, Marseille, France), corticotropin (ACTH, polyclonal, SigmaAldrich, St. Louis, MO, USA) and dopamine receptor type 2 (RD2 polyclonal, Merck Millipore, Darmstadt, Germany). The primary antibodies were applied in a working dilution of 1:100. The visualization of immunostaining was performed using Envision kit (Dako) with the use of 3,3' diaminobenzidine (DAB) as chromogen. A presence of more than $5 \%$ of immunopositive cells was considered as important. For a negative control, the primary antibody was omitted in the immunostaining procedure. The sections were viewed by a light microscope.

In a proportion of patients (37) with pituitary adenoma, the concentrations of insulin-like growth factor 1 (IGF-1) were estimated in blood serum by means of enzyme-amplified chemiluminescence immunoassay (EACLIA) on the Immulite 1000 analyser (Siemens, Warsaw, Poland) before surgery. The analytical sensitivity of the used assay was between $20 \mathrm{ng} / \mathrm{mL}$ and 1,600 ng/mL. Intra-assay coefficients of variation $(\mathrm{CV})$, depending on the concentration included in ranges from $3.1 \%$ to $4.3 \% \mathrm{ng} / \mathrm{mL}$ and inter-assay CV was between $5.8 \%$ and $8.4 \% \mathrm{ng} / \mathrm{mL}$.

The study was approved by the Bioethical Committee of the Medical University of Lodz, Lodz, Poland, decision RNN/99/15/KE.

Statistical analysis. The data obtained from the experiment was recorded on Excel (MS Office 2019) worksheets Basic descriptive statistics (mean \pm SEM) were calculated. A statistical analysis was performed using programs included in the statistical package Statistica 13.1 (Statsoft, Krakow, Poland). The differences between mean values were evaluated by Student's t test and for sets of categorical data Pearson's chi square test was applied. The quantitative parameters were expressed as mean value \pm standard deviation. Statistical differences between the tested values were considered as significant level of $\mathrm{p}<0.05$.

\section{Results}

The tumours derived from 62 patients (33 women and 29 man, mean age $57.4 \pm 11.8$ y) and diagnosed before surgery as CNFPAs. The immunohistochemical examination of removed pituitary adenomas was performed. Among them 23 (37.1\%) presented the positive immunoreaction of the at least $10 \%$ adenoma cells with anti-prolactin antibody (Fig. 1A). These cases concerned 16 women and 7 men $(69.6 \%$ and $30.4 \%$, respectively) and gender difference were statistically significant $-p<0.01$ (Fig. 2). The prevalence of feminine sex is specific for PRL-expressing CNFPA because the whole group of CNFPA included almost the same number of women and men. The PRL-positive and PRL-negative patients did not differ significantly in age (PRL-positive mean \pm SEM 56.52 $\pm 2.26 \mathrm{y}$; PRL-negative $58.95 \pm 1.90 \mathrm{y}$ ). Only in two cases (one woman and one man), the PRL was the unique hormone expressed in the tumour. In the remaining adenomas PRL immunopositivity was accompanied by $\mathrm{GH}$ expression -17 , $\mathrm{LH}$ or free $\beta \mathrm{LH}-13, \mathrm{FSH}$ -2 , free $\alpha$ subunit -4 or by ACTH -5 tumours (Fig. 1B, C). Seven adenomas were recurrent (7/23, $30.43 \%$ ) in PRL-immunopositive group and it is a higher value in comparison with PRL-immunonegative recurrent CNFPAs $(5 / 39,12.8 \%)$, but this difference is not statistically significant (Fig. 3).

\section{Presence of dopamine D2 receptors (RD2)}

RD2 were detected in 32 adenomas. In all PRL-immunopositive (21 cases) and all PRL-immunonegative (11 cases) examined tumours the positive immunostaining was found (Fig. 4).

\section{Insulin-like growth factor (IGF-1) serum concentration}

IGF-1 was measured in 37 patients with CNFPAs. In monohormonal silent prolactinoma, only in one case IGF-1 was measured (man, 45 y, 117 ng/mL - normal value). In the PRL-immunopositive adenomas $(\mathrm{n}=15)$, the mean IGF-1 serum concentration was $115.3 \pm 4.7 \mathrm{ng} / \mathrm{mL}$. In PRL-immunonegative CNFPAs the mean IGF-1 concentration was slightly 

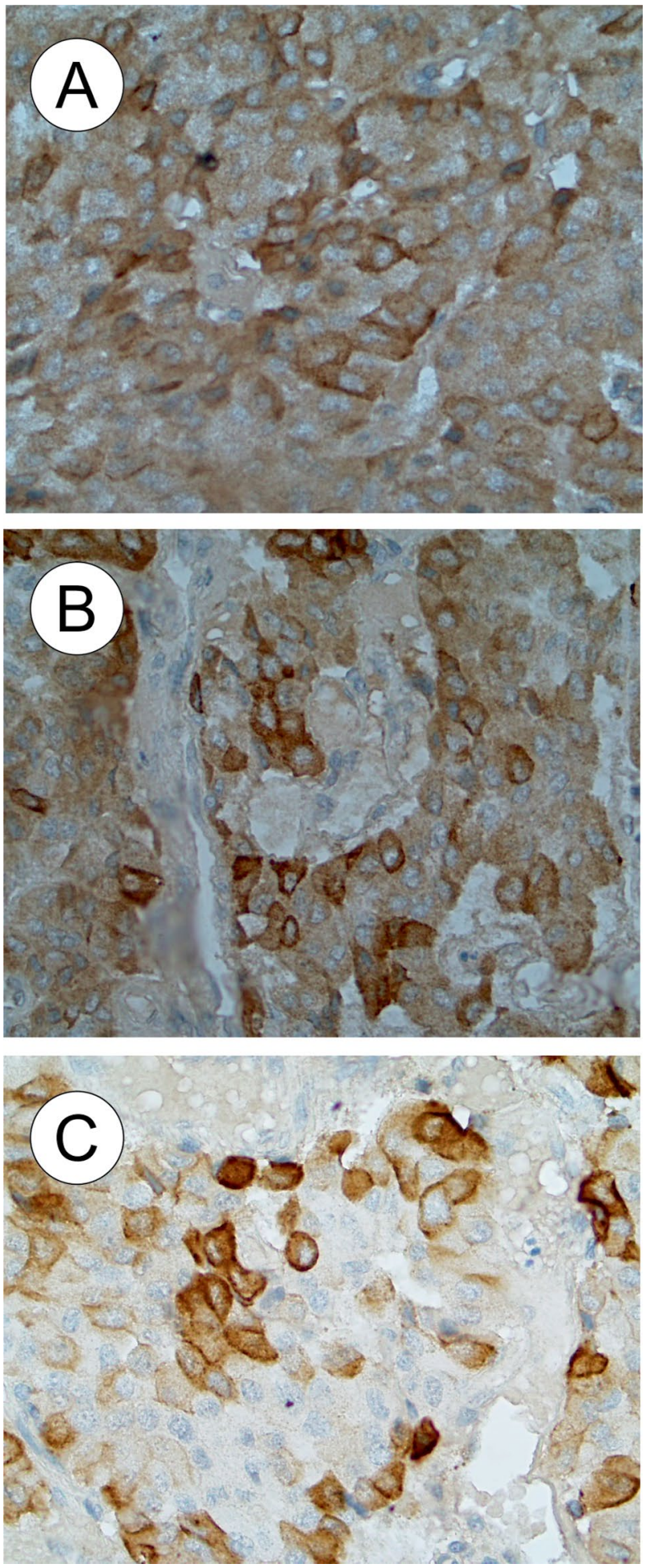

Figure 1. Immunohistochemical examination of clinically non-functioning pituitary adenoma in a 71-year-old man. Positive immunoreactions for: $\mathbf{A}$ - prolactin, $\mathbf{B}$ - growth hormone, C - alpha subunit. Original magnification $400 \times$.

lower $(102.1 \pm 17.5 \mathrm{ng} / \mathrm{mL})$; however, the difference is not statistically significant ( $p>0.05$ ). Because PRL immunopositivity occurs often with co-expression of

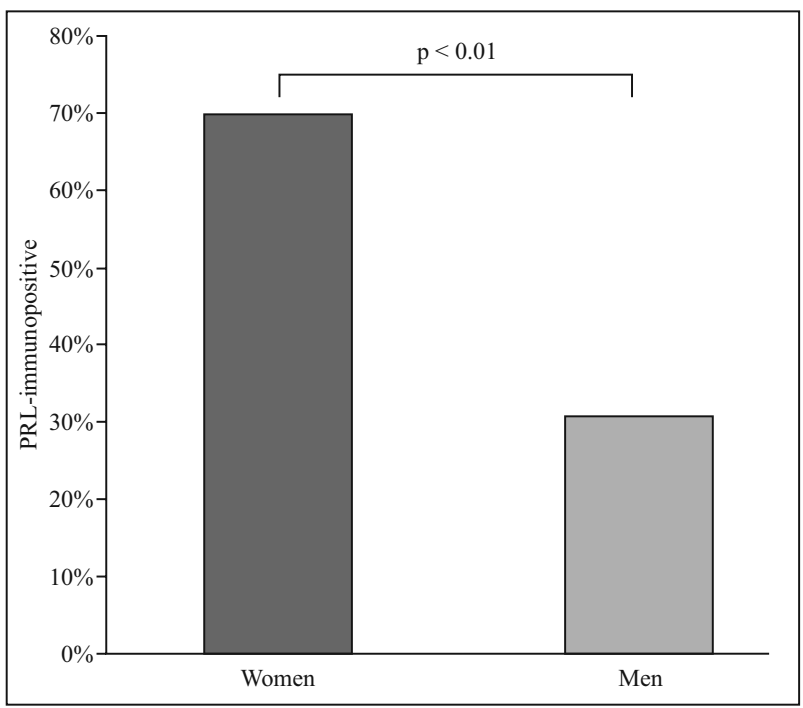

Figure 2. The percentage (\%) of women (16/23) and man (7/23) with PRL-immunopositive pituitary adenomas.

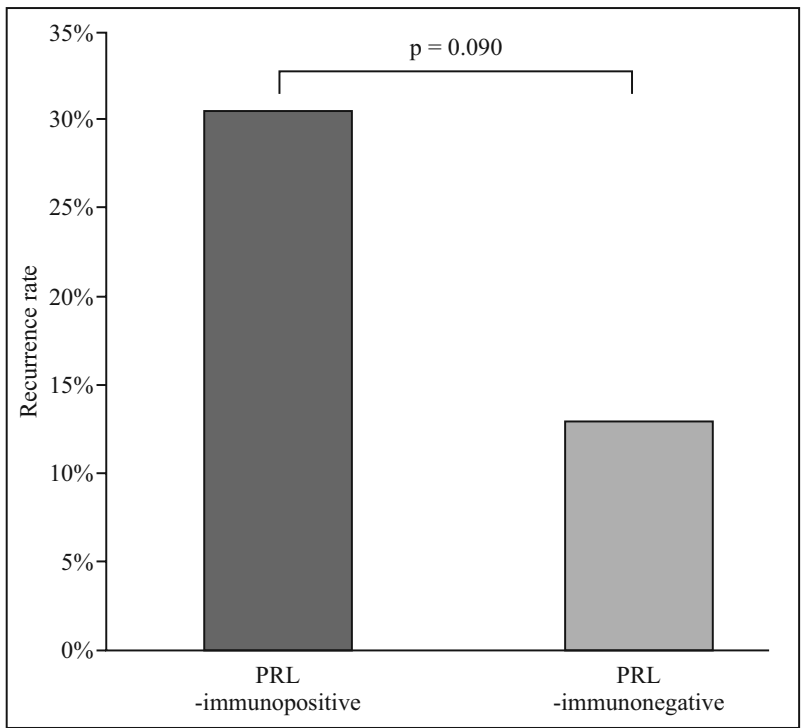

Figure 3. The number $(\%)$ of recurrences in PRL-immunopositive adenomas $(7 / 23,30.43 \%)$ and in PRL-immunonegative CNFPAs $(5 / 39,12.8 \%)$.

GH, we also compared IGF-1 serum levels in patients with GH-immunopositive and GH-immunonegative tumours. The difference was statistically significant $(127.9 \pm 20.75 \mathrm{ng} / \mathrm{mL}$ vs. $67.3 \pm 9.9 \mathrm{ng} / \mathrm{mL}$, respectively, $\mathrm{p}<0.01$ ) (Fig. 5).

\section{Discussion}

Our data are concordant with the observations that monohormonal silent prolactinomas are exceedingly 

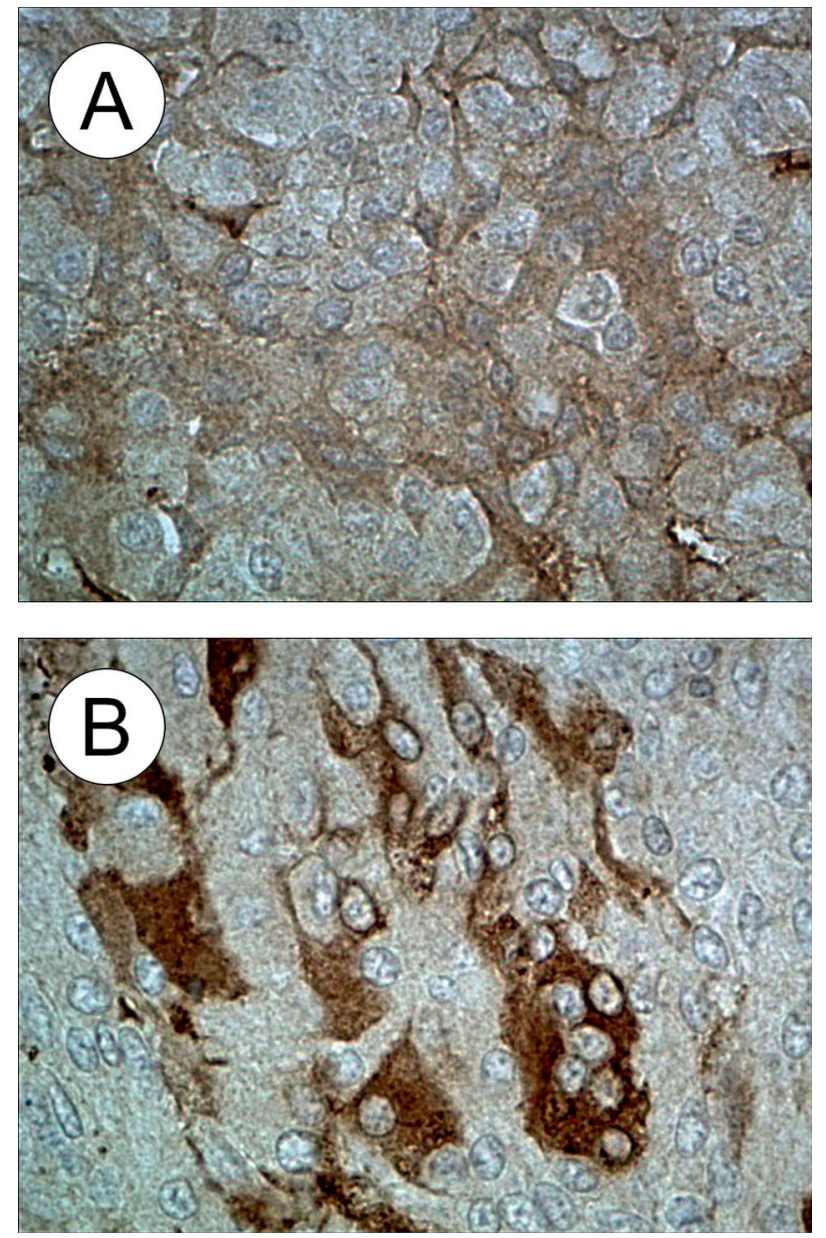

Figure 4. Positive immunostaining of dopamine receptors in PRL-immunopositive adenoma in a 60-year-old women) (A) and PRL-immunonegative adenoma in a 60-year-old man) (B). Original magnification $400 \times$.

rare $[5,7]$. Moreover, they corroborate also with the findings that the PRL expression is frequently combined with either silent or active expression of $\mathrm{GH}[5,7,19]$. This incidence is obvious because it is well known that lactotrophs and somatotrophs differentiate from the common progenitor cells under the influence of the same transcription factor (Pit-1). However, our novel observation is that the expression of PRL in CNFPA is frequently accompanied by gonadotropins, mostly by $\mathrm{LH}$ or free LH subunit. This combination is almost as frequent as that with $\mathrm{GH}$. The prevalence of feminine sex and their high recurrence rate is also worth notice. The former observation may be related to the frequent expression of oestrogen receptors in this type of adenoma [24]. The latter finding is more difficult to explain. However, the recurrent PRL-expressing tumours observed in this study were not monohormonal prolactinomas but were combined mostly with GH (4/7) and with

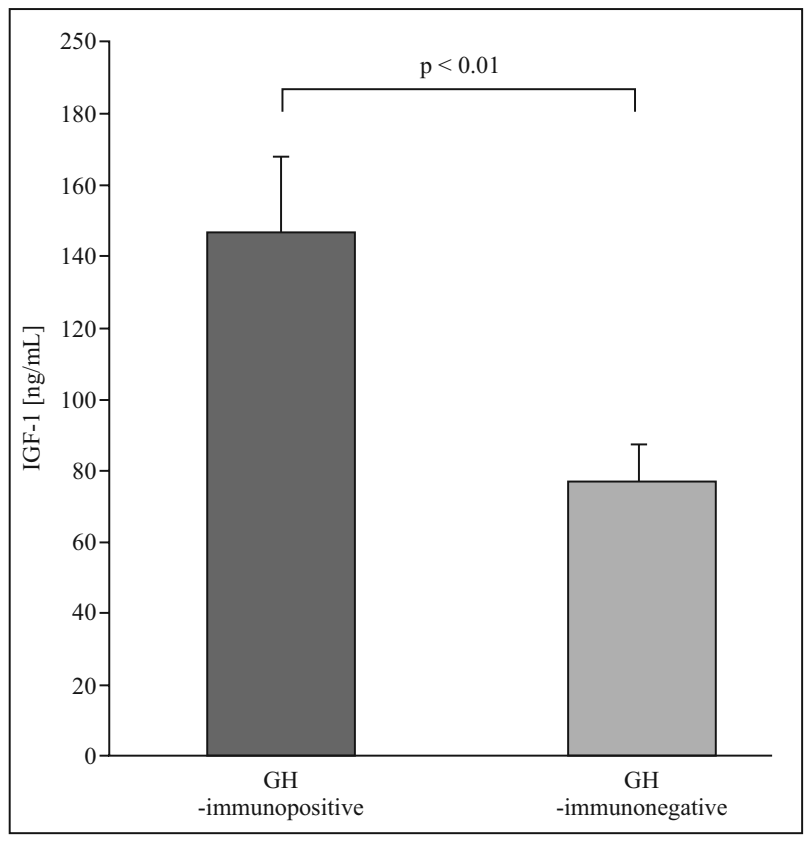

Figure 5. The mean IGF-1 serum levels in patients with PRL-immunopositive adenomas: comparison of the groups with $\mathrm{GH}$-positive and $\mathrm{GH}$-negative tumours.

gonadotropins (mostly with $\mathrm{LH}, 5 / 7$ ). The latter observation is concordant with the finding of Diri $e t$ al. [25] who found that that tumour recurrence rate is higher in LH-immunopositive in comparison with LH-immunonegative CNFPAs. Another factor that could be taken into consideration was a higher IGF-1 levels in silent GH-PRL adenoma than GH-immunonegative tumours (see below). Since the active prolactinomas are known to express the functional dopamine receptors and are in majority sensitive to pharmacological treatment by dopamine agonists, we wanted to see whether the silent prolactinomas express RD2 more frequently that PRL-immunonegative CNFPAs. Surprisingly, RD2 were detectable by immunohistochemistry in all cases of CNFPAs, irrespectively of the presence or absence of PRL immunostaining. This result is identical with that observed by Vieira et al. [26] who found the presence of RD2 mRNA as well as RD2 immunostaining in the all examined CNFPAs. The high frequency of RD2 in CNFPAs (approx. 70\%) was also reported in the other studies $[27,28]$. These results corroborate with the reported efficacy of the postoperative treatment of CNFPAs with dopamine agonists [27, 29, 30]. Our observation that the expression of RD2 concerns equally PRL-positive as PRL-negative CNFPAs suggests that the latter are also good candidates for the treatment with dopamine agonists. The last question worth to discuss is the relationship of PRL immu- 
nopositivity and IGF-1 secretion. It was found that patients with PRL-expressing CNFPAs have slightly higher preoperative IGF-1 concentrations in blood in comparison with those with PRL-immunonegative tumours. However, this fact is probably connected with the frequent coexistence of PRL and GH also in the case of silent adenomas. In an earlier study of our team it was found that in acromegaly the IGF-1 preoperative levels are significantly higher in somatoprolactinomas than in 'pure' somatotropinomas [31]. This observation, together with the results of the present study, corroborate with the experimental investigations showing that IGF-1 enhances the proliferation of lactotrophs in murine pituitary cells in vitro [32] and may induce the differentiation of lactotrophs from their progenitor cells [33]. It was also shown that IGF-1 induces in vitro trans-differentiation of somatotrophs into lactotrophs in the rat pituitary cell line $\mathrm{MtT} / \mathrm{S}[34,35]$.

To sum up, the non-functioning PRL-expressing pituitary adenomas very rarely present themselves as monohormonal silent prolactinomas but are relatively frequent as combined PRL-GH or plurihormonal tumours expressing also other pituitary hormones (mostly LH). The higher recurrence rate of PRL-expressing CNFPAs, as observed in the present study, needs further studies on the larger material.

\section{Acknowledgements}

This study was supported by grant of Medical University of Lodz No. 503/3-015-04/503-51-001. The authors thank Professor Andrzej Radek, MD, PhD, and Professor Maciej Radek, MD, PhD for the providing of pituitary adenoma samples.

\section{Conflict of interest}

The authors declare no conflict of interest.

\section{References}

1. Wade AN, Baccon J, Grady MS, et al. Clinically silent somatotroph adenomas are common. Eur J Endocrinol. 2011; 165(1): 39-44, doi: 10.1530/EJE-11-0216, indexed in Pubmed: 21493729.

2. Mayson SE, Snyder PJ, Mayson SE, et al. Silent (clinically nonfunctioning) pituitary adenomas. J Neurooncol. 2014; 117(3): 429-436, doi: 10.1007/s11060-014-1425-2, indexed in Pubmed: 24676675.

3. Mayson SE, Snyder PJ. Silent pituitary adenomas. Endocrinol Metab Clin North Am. 2015; 44(1): 79-87, doi: 10.1016/j. ecl.2014.11.001, indexed in Pubmed: 25732644.

4. Mercado M, Melgar V, Salame L, et al. Clinically non-functioning pituitary adenomas: Pathogenic, diagnostic and therapeutic aspects. Endocrinol Diabetes Nutr. 2017; 64(7):
384-395, doi: 10.1016/j.endinu.2017.05.009, indexed in Pubmed: 28745610.

5. Manojlovic-Gacic E, Engström BE, Casar-Borota O. Histopathological classification of non-functioning pituitary neuroendocrine tumors. Pituitary. 2018; 21(2): 119-129, doi: 10.1007/s11102-017-0855-1, indexed in Pubmed: 29275530.

6. Ntali G, Wass JA. Epidemiology, clinical presentation and diagnosis of non-functioning pituitary adenomas. Pituitary. 2018; 21(2): 111-118, doi: 10.1007/s11102-018-0869-3, indexed in Pubmed: 29368293.

7. Drummond J, Roncaroli F, Grossman AB, et al. Clinical and Pathological Aspects of Silent Pituitary Adenomas. J Clin Endocrinol Metab. 2019; 104(7): 2473-2489, doi: 10.1210/ jc.2018-00688, indexed in Pubmed: 30020466.

8. Pawlikowski M, Kunert-Radek J, Radek A. Gonadotropinoma - a frequent subtype of the pituitary adenoma. Endokrynol Pol. 2000; 51: 77-81.

9. Asa SL, Ezzat S. Gonadotrope Tumors. Prog Mol Biol Transl Sci. 2016; 143: 187-210, doi: 10.1016/bs.pmbts.2016.08.005, indexed in Pubmed: 27697203.

10. Pawlikowski M, Jaranowska M, Fryczak J, et al. Blood serum concentrations of gonadotropins and $\alpha$-subunit in patients with gonadotropinomas in relation to the immunoreactivity of pituitary adenoma. Endokrynol Pol. 2018; 69(5): 526-529, doi: 10.5603/EP.a2018.0049, indexed in Pubmed: 30074232.

11. Reincke M, Allolio B, Saeger W, et al. A pituitary adenoma secreting high molecular weight adrenocorticotropin without evidence of Cushing's disease. J Clin Endocrinol Metab. 1987; 65(6): 1296-1300, doi: 10.1210/jcem-65-6-1296, indexed in Pubmed: 2824554.

12. Iino K, Oki Y, Matsushita F, et al. Immunohistochemical properties of silent corticotroph adenoma and Cushing's disease. Pituitary. 2007; 10(1): 35-45, doi: 10.1007/s11102007-0010-5, indexed in Pubmed: 17410413.

13. Pawlikowski M, Kunert-Radek J, Radek M. "Silent" corticotropinoma. Neuro Endocrinol Lett. 2008; 29(3): 347-350, indexed in Pubmed: 18580839.

14. Guttenberg KB, Mayson SE, Sawan C, et al. Prevalence of clinically silent corticotroph macroadenomas. Clin Endocrinol (Oxf). 2016; 85(6): 874-880, doi: 10.1111/cen.13146, indexed in Pubmed: 27346850.

15. Kovacs K, Lloyd R, Horvath E, et al. Silent somatotroph adenomas of the human pituitary. Amer J Pathol. 1989; 134: 345-353.

16. Trouillas J, Sassolas G, Guigard MP, et al. Somatotropic adenomas without acromegaly. Pathol Res Pract. 1991; 187(8): 943-949, doi: 10.1016/s0344-0338(11)81065-4, indexed in Pubmed: 1792190.

17. Yamada S, Sano T, Stefaneanu L, et al. Endocrine and morphological study of a clinically silent somatotroph adenoma of the human pituitary. J Clin Endocrinol Metab. 1993; 76(2): 352-356, doi: 10.1210/jcem.76.2.8432778, indexed in Pubmed: 8432778.

18. Naritaka H, Kameya T, Sato Y, et al. Morphological characterization and subtyping of silent somatotroph adenomas. Pituitary. 1999; 1(3-4): 233-241, doi: 10.1023/a:1009942122673, indexed in Pubmed: 11081203.

19. Matsuno A, Itoh J, Itoh Y, et al. Histopathological analyses of silent pituitary somatotroph adenomas using immunohistochemistry, in situ hybridization and confocal laser scanning microscopic observation. Pathol Res Pract. 2001; 197(1): 13-20, doi: 10.1078/0344-0338-00003, indexed in Pubmed: 11209812.

20. Pawlikowski M, Kuta J, Fuss-Chmielewska J, et al. ,Silent' somatotropinoma. Endokrynol Pol. 2012; 63(2): 88-91, indexed in Pubmed: 22538745. 
21. Pawlikowski M, Pisarek H, Jaranowska M, et al. „Silent” thyrotropin (TSH) expression in acromegaly and clinically non-functioning pituitary adenomas. Endokrynol Pol. 2016; 67(5): 515-518, doi: 10.5603/EP.a2016.0056, indexed in Pubmed: 27403655 .

22. Saeger W, Lüdecke DK, Buchfelder M, et al. Pathohistological classification of pituitary tumors: 10 years of experience with the German Pituitary Tumor Registry. Eur J Endocrinol. 2007; 156(2): 203-216, doi: 10.1530/eje.1.02326, indexed in Pubmed: 17287410.

23. Korol P, Jaranowska M, Pawlikowski M. Immunohistochemical demonstration of $\mathrm{LH} / \mathrm{CG}$ receptors in non-neoplastic human adrenal cortex and adrenocortical tumors. Folia Histochem Cytobiol. 2019; 57(1): 23-27, doi: 10.5603/FHC. a2019.0003, indexed in Pubmed: 30924919.

24. Mavrakis AN, Tritos NA. Diagnostic and therapeutic approach to pituitary incidentalomas. Endocr Pract. 2004; 10(5): 438-444, doi: 10.4158/EP.10.5.438, indexed in Pubmed: 15760793.

25. Kaptain GJ, Simmons NE, Alden TD, et al. Estrogen receptors in prolactinomas: a clinico-pathological study. Pituitary. 1999; 1(2): 91-98, doi: 10.1023/a:1009903603495, indexed in Pubmed: 11081186.

26. Diri H, Ozaslan E, Kurtsoy A, et al. Is Positive Staining of Non-Functioning Pituitary Adenomas for Luteinizing Hormone Associated with a Poor Prognosis? Turk Neurosurg. 2017; 27(1): 8-13, doi: 10.5137/1019-5149.JTN.14889-15.1, indexed in Pubmed: 27593756.

27. Vieira Neto L, Widemberg LE, Moraes AB, et al. Dopamine receptor subtype 2 expression profile in nonfunctioning pituitary adenomas and in vivo response to cabergoline therapy. Clin Endocrinol (Oxf). 2015; 82: 739-746, doi: 10.1111/cen.12684, indexed in Pubmed: 25418156.

28. Pivonello R, Matrone C, Filippella M, et al. Dopamine receptor expression and function in clinically nonfunctioning pituitary tumors: comparison with the effectiveness of cabergoline treatment. J Clin Endocrinol Metab. 2004; 89(4): 1674-1683, doi: 10.1210/jc.2003-030859, indexed in Pubmed: 15070930

29. Pawlikowski M. Immunohistochemical detection of dopamine D2 receptors in human pituitary adenomas. Folia Histochem Cytobiol. 2010; 48(3): 394-397, doi: 10.2478/v10042-010-0031-1, indexed in Pubmed: 21071344.

30. Cooper O, Greenman Y. Dopamine Agonists for Pituitary Adenomas. Front Endocrinol. 2018; 9, doi: 10.3389/ /fendo.2018.00469, indexed in Pubmed: 30186234.

31. Batista RL, Musolino NRC, Cescato VAS, et al. Cabergoline in the Management of Residual Nonfunctioning Pituitary Adenoma: A Single-Center, Open-Label, 2-Year Randomized Clinical Trial. Am J Clin Oncol. 2019; 42(2): 221-227, doi: 10.1097/COC.0000000000000505, indexed in Pubmed: 30540568.

32. Toszek J, Pawlikowski M, Jaranowska M, et al. Is preoperative level of insulin-like growth factor-1 (IGF-1) connected with immunohistochemical phenotype of pituitary adenoma in patients with acromegaly? Diagn Lab. 2019; 55: 1-6.

33. Oomizu S, Takeuchi S, Takahashi S. Stimulatory effect of insulin-like growth factor I on proliferation of mouse pituitary cells in serum-free culture. J Endocrinol. 1998; 157(1): 53-62, doi: 10.1677/joe.0.1570053, indexed in Pubmed: 9614357.

34. Hikake T, Hayashi S, Iguchi T, et al. The role of IGF1 on the differentiation of prolactin secreting cells in the mouse anterior pituitary. J Endocrinol. 2009; 203(2): 231-240, doi: 10.1677/JOE-09-0232, indexed in Pubmed: 19696100.

35. Inoue K, Sakai T. Conversion of growth hormone-secreting cells into prolactin-secreting cells and its promotion by insulin and insulin-like growth factor-1 in vitro. Exp Cell Res. 1991; 195(1): 53-58, doi: 10.1016/0014-4827(91)90499-k, indexed in Pubmed: 2055276.

Submitted: 14 February, 2020

Accepted after reviews: 15 June, 2020 Available as AoP: 29 June, 2020 